\title{
Quality Numerical Indicators of Raw Materials of Sanguisorba Officinalis L. Growing on Overburden Dumps of Kuzbass Coal Surface Mines
}

\author{
Natalya Egorova ${ }^{1}$, Irina Egorova, ${ }^{1,}{ }^{*}$, Elena Maltseva $^{2}$, and Andrey Sukhikh ${ }^{2}$ \\ ${ }^{1}$ The Federal Research Center of Coal and Coal Chemistry of SB RAS (Institute of Human Ecology \\ of the SB RAS), Leningradskiy avenue, 10, Kemerovo, 650065, Russia \\ ${ }^{2}$ Kemerovo State Medical University, Voroshilov street, 22a , Kemerovo,650056, Russia
}

\begin{abstract}
Medicinal plant materials quality assessment of the Sanguisorba officinalis L. growing on the Kedrovsky coal mine dumps in Kemerovo region is given. The analysis of obtained burnet raw material quality indicators (moisture, total ash, insoluble in hydrochloric acid, quantitative content of tannins, heavy metals, radionuclides) showed that this vegetable raw material match with the requirements of PhI.2.5.0078.18 "Sanguisorba officinalis L. rhizome and roots". Tannins average content in the burnet rhizomes and roots was $15.708 \pm 0.307 \%$, which is within the normal range (up to $14 \%$ ). It was found that the heavy metals $(\mathrm{Pb}, \mathrm{Cd}, \mathrm{Hg}$ ) content does not exceed the MPC adopted for medicinal plant raw materials (G.Ph.A.5.5.000.0009.15). The obtained indicators for the artificial radionuclides (Cs-137, Sr-90) content showed that their quantity in the raw material is also within the normal range and their actual content is several times less than the normalized one. From the point of radiological safety view the studied raw materials are not dangerous since they accumulate $0.36 \% \mathrm{Sr}-90$ and $0.42 \%$ Cs- 137 from the levels established by regulatory documentation. Therefore, the burnet medicinal plant raw material harvested at the Kedrovsky open-pit coal mine on the territory of waste dump does not represent a danger to human health.
\end{abstract}

\section{Introduction}

A Rosaceae family (Rosaceae) representative (Sanguisorba officinalis L.) is found among the herbaceous plant on the Kuzbass coal mines rock dumps. The burnet thicket is marked mainly on meadows, in inter-dump depressions, on the dumps tops in the rock heaps of Kedrovsky mine cut territory. The plant prefers mainly loams [1,2]. Although it does not form commercial thickets, the local population produces a medicinal plant raw material harvesting of Sanguisorba officinalis L.

The burnet rhizomes and roots (Rhizoma cum radicibus Sanguisorba) are pharmacopoeial raw materials. The raw materials value is determined by the complex of

${ }^{*}$ Corresponding author: nir_kem@mail.ru 
biologically active substances - tannins, ellagitannins, proanthocyanidins, catechins, flavonoids, phenol carboxylic acids, triterpene glycosides, oleanolic and ursolic acids derivatives, polysaccharides, saponins, sangvisorbin, poterin, sterols, colorants, essential oils, etc. [3-7].

Due to the rich chemical composition of greater burnet medicinal raw materials and drugs based on it have a broad spectrum of pharmacological action. It is used as a hemostatic agent for various kinds of bleeding, for rinsing the throat, in the treatment of stomatitis and gingivitis, as an astringent for gastrointestinal diseases [3-5] etc. In addition, the greater burnet polyphenolic complex has P-vitamin and anti-hypoxic activity, with a clearly pronounced stimulating effect on the heart [5]. Recent studies have shown that extracts derived from this plants have anti-cancer and antioxidant activity [8-12]. This raw material is also used in homeopathic practice ("Sanguisorba"), and as a part of dietary supplements ("Burnet", "Burnet Root") [3].

In traditional medicine not only the burnet underground organs are used but also herb, leaves, and flowers. The greater burnet leaves based decoction is used in the upper respiratory tract diseases treatment, in particular pulmonary tuberculosis, which may be complicated by bleeding. A leaves and flowers decoction used for the hemorrhoids treatment, the gastrointestinal tract diseases (enterocolitis, dysentery, ulcerated if, etc.). East traditional practitioner treat malignant tumors with its help [4].

Due to the presence of biologically active compounds various classes, Sanguisorba officinalis L. is a promising type for further study and new drugs development [13]. The burnet raw material has been widely used in the production of combined and enriched feed in recent years.

Earlier studies of the environmental and hygienic evaluation some of the raw materials (Hippophae rhamnoides L., Taraxacum officinale Wed., Rosa majalis Herrn. Et al.), including Sanguisorba officinalis L. raw materials growing on the Kuzbass coal mines dumps showed their safety [14-19].

In addition, it is known that the biologically active compounds content in plants is affected by growing areas witch subject to strong anthropogenic influences [7, 17].

Therefore it was in interest to evaluate the Sanguisorba officinalis L. medicinal raw material quality that grows in the coal mines dumps to expand the resource base and improve the provision with valuable natural plant materials for the local population.

The goal of this work is to determine the Sanguisorba officinalis L. raw materials (rhizomes and roots) quality numerical indicators growing on the Kedrovsky open-pit coal mine rock dumps.

\section{Materials and Methods}

The objects of study were the greater burnet rhizomes and roots collected in the summer season in the period 2017-2018 on the "Yuzhny" rock waste of Kedrovsky coal mine in Kemerovo region. Waste age is $35-40$ years. The total square of this waste is 599.3 hectares. The relief is flat-inclined. Rocks, which the waste disposal areas consist of, are mainly represented by sandstones $(60 \%)$, siltstones $(20 \%)$, argillites $(15 \%)$, loams and clays $(5 \%)$. The predominant fraction is the large aggregates (from 3 to $10 \mathrm{~mm}$ and more), presents of small are reduced. Embryozems are heavy, medium-rich loams (humus $3.5 \%$ ), a characteristic feature of which is the phosphorus and nitrogen mobile forms low availability $(1.7-7.0 \mathrm{mg} / \mathrm{kg})$. The exchangeable potassium content $(125 \mathrm{mg} / \mathrm{kg})$ is slightly below the norm [7].

Raw materials were harvested during the dry time of the day, according to generally accepted rules, with no visible signs of damage. The raw materials were dried by the air- 
shady method. In accordance with G.Ph.A.1.005.15, an average sample was prepared by the quartering method $[\mathrm{Ph} 14 \mathrm{lp}]$. The average sample mass tolerances did not exceed $\pm 10 \%$.

The numerical indicators of raw materials quality (humidity, total ash, insoluble ash in hydrochloric acid, tannin content) were evaluated in accordance with the State Pharmacopoeia XIV publication requirements [20].

The tannins quantitative determination in raw materials was carried out according to Federal Standard 1.53.008.18 "Method 1. Tannins determination in recount to tannin" [20]. Raw materials water extract was used as a test solution. Before analysis the raw materials dried to constant weight were crushed to a particle size passing through a $3 \times 3 \mathrm{~mm}$ sieve. The tannins amount was calculated in percent in recount to the absolute dry raw material.

Tannins presence confirmation in the studied greater burnet raw material samples was performed using identification test. For this purpose, water extracts were prepared from an air-dry raw material at a ratio of 1:10 in accordance with the requirements of the State Pharmacopoeia IX [21].

The studies were carried out in the recultivation and biomonitoring laboratory FIC UUK SB RAS.

Analysis by heavy metals $(\mathrm{Pb}, \mathrm{Cd}, \mathrm{Hg})$ and radionuclides ( $\mathrm{Sr}-90, \mathrm{Cs}-137)$ definition in raw materials was carried out in the agrochemical service "Kemerovo" accredited test center.

Elemental analysis was performed using the atomic absorption method on AAS instruments - 30 by Karl Ceis Jena (Germany).

Radioactivity was performed according to the "Method of measuring radioactivity in counting samples using the software "Progress" approved by VNIIFTRI on December 22, 2003 at a spectrometric complex for measuring the activity of alpha, beta - and gamma radiating nuclides "Progress".

Analyses were performed in three replications; results were statistically processed using Statistica 6.0 software.

\section{Results and Discussion}

Qualitative analysis confirmed the presence of tannins in the medicinal raw materials analyzed samples. It was found that they have a predominantly hydrolyzable nature, which is consistent with previously obtained results [22]. The qualitative analysis results are presented in Table 1.

Table 1. The results of tannins qualitative reactions in Sanguisorba officinalis L. extraction from raw materials (rhizome and roots).

\begin{tabular}{|c|c|c|}
\hline $\mathbf{N}$ & Reagent & Observed Reaction Effect \\
\hline 1. & $1 \%$ gelatin solution & Dregs disappearing from excess reagent \\
\hline 2. & $\mathrm{NaNO}_{3}$ & Brown coloring \\
\hline 3. & Ferrous ammonium sulfate & Black - blue coloring \\
\hline 4. & $10 \%$ lead acetate normal salt solution & Black - blue coloring \\
\hline
\end{tabular}

The summarized determining results for the quality the Sanguisorba officinalis L. rhizomes and roots numerical indicators are presented in Table 2 . 
From the data presented in Table 2, it can be seen that humidity, total ash, and ashes insoluble in 10\% hydrochloric acid do not exceed the established standards.

The tannins average content in the greater burnet raw material was $15.708 \pm 0.307 \%$, which corresponds to the quality requirements (Table 2).

Table 2. Guality and safety indicators of Sanguisorba officinalis L. rhizomes and roots in conditions of the Kedrovsky open-pit coal mine waste dump (average data).

\begin{tabular}{|c|c|c|c|c|}
\hline $\mathbf{N}$ & \multicolumn{2}{|l|}{ Indicators } & Test & $\begin{array}{c}\text { Requirements } \\
\text { [S.PH. 14] }\end{array}$ \\
\hline 1. & \multicolumn{2}{|l|}{ Humidity, \% } & $7.570 \pm 0.245$ & not more than 13 \\
\hline 2 . & \multicolumn{2}{|l|}{ Total ash, $\%$} & $8.259 \pm 0.252$ & not more than 12 \\
\hline 3. & \multicolumn{2}{|l|}{ Ash, not soluble in HCL, \% } & $4.501 \pm 0.262$ & not more than 5 \\
\hline 4. & \multicolumn{2}{|l|}{ The tannins amount, $\%$} & $15.708 \pm 0.307$ & not more than 14 \\
\hline \multirow[t]{3}{*}{5 . } & \multirow[t]{3}{*}{ * Heavy metals, mg/kg: } & $\mathrm{Pb}$ & $0.740 \pm 0.060$ & 6.0 \\
\hline & & $\mathrm{Cd}$ & $0.040 \pm 0.008$ & 1.0 \\
\hline & & $\mathrm{Hg}$ & $0.015 \pm 0.002$ & 0.1 \\
\hline \multirow[t]{2}{*}{6.} & \multirow{2}{*}{$\begin{array}{l}* * \\
\text { radionuclide } \text { Permissible } \\
\text { activity, } \mathrm{Bq} / \mathrm{kg}, \quad \text { not } \\
\text { more than }\end{array}$} & $\begin{array}{l}\text { Cs- } \\
137\end{array}$ & $1.650 \pm 0.200$ & 400 \\
\hline & & Sr-90 & $0.720 \pm 0.030$ & 200 \\
\hline
\end{tabular}

Heavy metals $(\mathrm{Pb}, \mathrm{Cd}, \mathrm{Hg})$ content numerical indicators in the raw materials show that the pollutants concentration in the greater burnet rhizomes and roots does not exceed the established standards and their actual content is several times less than the normalized (Table 2).

The radionuclides (Sr-90 and Cs-137) content obtained data in raw materials is less than a multiyear average and range from 0.72 to $1.65 \mathrm{~Bq} / \mathrm{kg}$ (Table 2).

From the point of radiological safety view, the greater burnet rhizomes and roots do not pose a danger to human life and health, since they accumulate only $0.36 \%$ of Sr-90 and $0.42 \%$ of Cs- 137 from the levels established by regulatory documentation.

\section{Conclusion}

Thus, the Sanguisorba officinalis L. raw material harvested on the "Yuzhny" rock waste of Kedrovsky coal mine analysis showed that its rhizomes and roots, according to all studied parameters: moisture, total ash, ash insoluble in hydrochloric acid, the content of tannins, comply with the requirements of $\mathrm{PhI}$ 2.5.0078.18 "Sanguisorba officinalis L. rhizome and roots" and does not pose a danger to human life and health.

It should be noted that the question of the using medicinal plant raw materials possibility must be addressed at the certification stage in each individual case. 
The work was carried out according to the state task - No 0352-2019-0015

\section{References}

1. Yu. A. Manakov, T. O. Strelnikova, A. N. Kupriyanov, The Formation of Plant Cover in Man-Made andscapes of the Kuznetsk Basin (Novosibirsk, SO RAN, 2011)

2. I. N. Egorova, The possibility of using the reclaimed lands of the coal mine "Kedrovskii" for the harvesting of medicinal plant raw material (KemSU, Kemerovo, 2011)

3. D. A. Muraveva, I. A. Samilina, G. P. Yakovlev, Pharmacognosy (Medicine, Moscow, 2002)

4. S. Ya. Sokolov, I. P. Zamotaev, Handbook of medicinal plants (Metallurgy, Moscow, 1989)

5. G. R. Azovcev, A. A. Zikov, T. A. Kukushkina, The garden burnet Polyphenolic complex as a capillary-protective agent (Science Dumka, Kiev, 1988)

6. E.M. Maltseva, N.O. Egorova, I.N. Egorova. Vestn. Ural. Med. Akad. Nauki. 3:1, 68, (2011)

7. N. O. Egorova, The Greater burnet tannins quantitative content, depending on the place of growth (KemSU, Kemerovo, 2006)

8. E. M. Maltseva, N. O. Egorova, I. N. Egorova, N. A. Zenina, O. A. Ivanova, Greater burnet rhizomes and roots dry extract antimicrobial activity (WSU, Voronezh, 2018)

9. E. M. Maltseva, N. O. Egorova, I. N. Egorova, R. A. Mukhamadiyarov, J. Medicine in Kuzbass, 2, 32-38 (2017)

10. N. O. Egorova, E.M. Maltseva, I. N. Egorova, O. N. Egorova, N. B. Serikova, J. Modern problems of science and education, 3, 14. (2018)

11. N. O. Egorova, S. A. Sheremetova, Sanguisorba officinalis L complex use, growing on the territory of the Kemerovo region (KemSU, Kemerovo, 2017)

12. N. Egorova, I. Egorova, E. Maltseva, A. Sukhikh, E3S Web Conf., 26, 02023 (2018)

13. I. N. Egorova, O. A. Neverova, J. Orenburgskii Gosudarstvennyi Universitet. Vestnik, $10: 185,385-387(2015)$

14. N. O. Egorova, O. A. Neverova, I. N. Egorova, J. Modern problems of science and education, 6, 1373 (2014)

15. O. A. Neverova, I. N. Egorova, J. Food Processing: Techniques and Technology, 3:38, 139-146 (2015)

16. I. N. Egorova, O. A. Neverova, T. I. Grigoreva, J. Modern problems of science and education, 3, 592 (2015)

17. I. N. Egorova, O. A. Neverova. World Applied Sciences Journal, 27, 497-500 (2013)

18. Z. Zhao, X. He, Q. Zhang, X. Wei, L. Huang, J.C. Fang, X. Wang, M. Zhao, Y. Bai, X. Zheng, Am. J. Chin. Med., 45, 89-96 (2017)

19. S. Zhang, X. Liu, Z. L. Zhang, L. He, Z. Wang, G. S. Wang, J. Molecules, 23, 133-147 (2012)

20. Russia State Pharmacopoeia 14 (XIV) T.1V (Medicine, Moscow, 2018)

21. Russia State Pharmacopoeia 11 (XI), T.2 (Medicine, Moscow, 1990)

22. N. O. Egorova, The Greater burnet (Sanguisorba officinalis L.) tannins content estimation in the raw material in a culture in the Kuzbass Botanical Garden (KemSU, Kemerovo, 2018) 